\title{
Relationships among US S\&P500 Stock Index, its Futures and NASDAQ Index Futures with Volatility Spillover and Jump Diffusion: Modeling and Hedging Performance
}

\author{
Hsiang-Hsi Liu ${ }^{1}$ and Yu-Cheng Lin ${ }^{2}$
}

\begin{abstract}
This study takes the US S\&P500 stock index cash, futures and NASDAQ stock index futures as the main research objects, and applies the ARJI (autoregressive jump intensity model) VEC GJR-GARCH model to examine the co-integration, volatility spillover, jump behavior and hedge performance of the three markets. With the rapid circulation of new information, the financial market will often fluctuate under the impact of new information. Investors will have different and timely responses to emergencies, and this event will have an impact on the stock market. When the event is unexpected or abnormal, the financial market will have huge fluctuations, and this kind of fluctuation is a jump. The empirical results found that the three markets have linkages and volatility spillover effects, and there are indeed discontinuous jumps. Two-way volatility spillovers between S\&P500 index cash and futures, and only one-way volatility spillovers from S\&P500 futures to the Nasdaq futures market. International investors need to consider information from their own-market volatility (risk) as well as information on volatility spillovers (risk) from other markets. The jump frequency is not a fixed constant, that is, the jump frequency (strength) generated by abnormal information changes over time. In addition, the results of this research also found that the ARJI VEC GJR-GARCH model can better capture the risk of fluctuations in price discontinuities after adding jump factors to the hedging performance estimated by the ARJI VEC GJR-GARCH model. The hedging performance can be more effective, which is conducive to investors' risk management decisions. Also, the performance of direct hedging that is better than the performance of cross hedging.
\end{abstract}

JEL classification numbers: F30, G10, G13, G19

Keywords: Jump Intensity, Jump Size, Co-integration, ARJI, VEC GJR-GARCH, Hedging Ratio, Hedging Performance.

1 Distinguished Professor, Graduate Institute of International Business, National Taipei University, Taiwan

2 Master, Graduate Institute of International Business, National Taipei University, Taiwan 


\section{Introduction}

Facing the trend of liberalization and internationalization, not only the domestic spot and futures markets are deeply affected by the operation of the US spot and futures markets, but domestic and international investors may also consider US futures as a portfolio or hedging tool while purchasing domestic futures. Since the US stock market is a global information center, the risk aversion information and risk aversion strategies derived from the correlation analysis of its futures and spot operations can be extended to domestic investors as investment references, therefore this study applies the US S\&P500 stock price index futures spot correlation analysis to discuss the effect of direct hedging has also been further added to the study of NASDAQ index futures as cross hedging, and the prospects for futures as hedging tools have more hedging performance. These are the main research issues of this study.

The US financial market has always been an important source affecting the global and Taiwanese financial markets. Often the US announced an important policy or an unexpected events that would have an impact on the global and Taiwanese financial markets. S\&P500 index futures is a stock index futures contract traded on Chicago Mercantile Exchange (CME). It is the most actively traded index futures in the US financial market. This index contains many companies, has more diversified risks, and can better reflect broader market changes. Therefore, institutional investors often use S\&P500 index futures as an important tool for hedging risks in investment positions, as well as an effective tool for domestic general investors to lock in loss risks and stabilize investment profits. Because most of the S\&P500 price index is industrial stocks, the NASDAQ index futures, which focuses on high-tech stocks, are also used to observe their cross-hedge performance. This study will take the S\&P500 stock index as the main object, and then use S\&P500 and NASDAQ index futures as the hedging objects, and apply the ARJI VEC GJR-GARCH model constructed in this study to explore the interaction, volatility spillover and jump phenomenon of these three markets, and compare the hedging ratio and performance to effectively propose price discovery and hedging strategies.

Due to the advancement of technology, investors have more diversified channels to obtain new information. Coupled with the opening of the international financial market and the lifting of investment restrictions, capital flows rapidly. Whenever a special event occurs in a world powerful economic country, the entire world market will fluctuate greatly. Volatility and risk can be linked with new stock market news. An expected or unexpected latent news will cause the stock market to fluctuate. When volatility and risk can be linked with new stock market news, an expected or unexpected latent news will cause volatility in the stock market. From this point of view, the biggest factor causing price fluctuations is the impact of potential news. Potential news can be divided into two parts: normal news and abnormal news (unusual news). The normal news assumes that the conditional variance of the return will change smoothly and gradually; the abnormal news (unusual news) will cause a large change in the return. These 
abnormal news (information) that has an impact on the market are defined as jumps. Anything that causes a jump in the market may be a major event. In order to avoid the risks caused by such unexpected events, hedging becomes more important topic for financial research (Eraker (2004), Chan and Young (2006), Bertus, Godbey and Hilliard (2009), Liu, Chng and Xu (2014), Fan, Luo and Wu (2017)). Recently, Koulis, Kaimakamis and Beneki (2018) explored hedging effectiveness for international index futures markets using daily settlement prices for the period 4 January 2010 to 31 December 2015 to analyze sample consists of daily closing market rates of the stock cash indexes of the USA and the European futures contracts. They applied OLS regressions, Error Correction Model (ECM) and Autoregressive Distributed Lag (ARDL) co-integration model to estimate corresponding hedge ratios and examine hedging effectiveness. The research results show that if the ARDL model is used to estimate the time-varying hedging ratio, it is more effective than the fixed hedging ratio in minimizing risk. Lai (2019) attempted to evaluate hedging performance through multivariate GARCH models, and constructed conditional covariance matrices by different methods, such as BEKK (Baba_Engle_Kraft_Kroner), GO (generalized orthogonal) and DCC(dynamic conditional correlation). Using the daily spot and futures data of the stock index from January 1995 to April 2012 to estimate the hedge ratio, in general, empirical evidence favors the GO model for estimating the hedge ratio because the specification enables flexible dynamics in the modeling of the return process.

Over the past few decades, there have been several phenomena that illustrate the behavior of market returns. The most important of these empirical findings is that the martingale difference sequence and conditional variance will change over time and the distribution of unconditional variance will show a phenomenon of leptokurtosis. Regarding the dynamic change of conditional variance, GARCH (generalized autoregressive conditional heteroscedasticity), GJR-GARCH (Glosten, Jagannathan and Runkle, 1993) and stochastic volatility (SV) models have been used to explain. Both the GARCH and SV models are used to capture the smooth and persistent changes of volatility, while the GJR-GARCH model can capture the volatility asymmetry of good and bad news in the market. However, these models are not sufficient to explain the discontinuity of asset return fluctuations, that is, they do not consider the effect of jump frequency and jump amplitude. Most capital returns have discrete jumps. The establishment of the GARCH-jump model can better capture the statistical characteristics of discrete jumps.

As for the GARCH-jump process, Press (1967) first used the basic Poisson jump model to measure stock price returns. He called it the compound events model. This model can estimate the aggregation of the changes in price within a fixed time interval (the aggregation of a random number of price changes in a fixed time interval). Press (1967) assumed that the number of events causing price changes conforms to the Poisson distribution, and the average number of events that occur is called the jump intensity or jump frequency. An instantaneous jump in asset returns that reflects abnormal market information is called jump size. 
In recent years, the basic Poisson Jump Model has been applied to the empirical studies of volatilities in many different financial markets (Craine, Lochstoer and Syrtveit (2000), Andersen, Benzoni and Lung (2002), Eraker (2004), Kaeck and Alexander (2013), Cheang, Chiarella and Ziogas (2013) and Byun, Jeon, Min, and Yoon (2015)). Chan and Young(2006), Todorov (2009), Creel and Kristensen (2015) and Zhou, Wu and Wang (2019) used the continuous time jump model and the simulation method to study the changes or correlation of stock and foreign exchange, options or stock market cash returns. In the above-mentioned related literature research, it is pointed out that due to the event or government intervention, the remuneration changes or the correlation jump occurred during the event. The jump-diffusion model is used to estimate the jump probability and jump intensity to explore the impact on the relevant financial market when a major event occurs. The abnormal reaction caused by empirical evidence shows that the stock and foreign exchange market, options or stock index futures cash market has an increased probability of jumping when a major event occurs, and the number of variations in the size of the jump is larger than usual. Generally, the intuitive assumption for the jump model is that the jumping probability is fixed, which is biased. In fact, the jump probability will change over time.

In order to capture the phenomenon of jump and diffusion effects in the market and calculate the hedging ratio based on the minimum variance hedging criterion, the econometric model used must be able to accurately describe the fluctuation of the stock price return in line with the skew and peak diffusion process. Therefore, conditional heteroskedasticity and jump-diffusion process are two major topics that discuss the distribution pattern of stock price returns. Therefore, conditional heteroskedasticity and jump-diffusion process are two major topics in the discussion of the distribution pattern of stock price return. Focusing on this, this study integrates the ARJI model (autoregressive jump intensity model) and the GJR-GARCH model, i.e., ARJI VEC GJR-GARCH, to explore the correlation between S\&P500 stock index cash and futures and NASDAQ index futures, as well as the effect of volatility spillover with jump phenomena, supplemented by Chan and Maheu (2002), Maheu and McCurdy (2004), Chan and Young (2006), Byun, Jeon, Min, and Yoon (2015) and Ulyah, Lin and Miao ( 2018), considering the discontinuity of the jump between futures and cash prices and incorporating it into the calculation of the hedge ratio. It is hoped that with both efficiency and accuracy, investors and financial institutions can make correct hedging decisions when making portfolio selection, and relevant information can also provide the government agencies to formulate relevant policies and implement the futures market to operate effectively in arbitrage and price discovery.

The remaining of the study is organized as follows. Section 2 describes the conceptual framework of ARJI model and estimation method. Section 3 discusses the empirical results and implications. Section 4 presents the concluding remarks. 


\section{Conceptual Framework of ARJI Model and Estimation Method}

The traditional assumption of the return on assets follows a continuous random diffusion process, which can be shown in Equation (1):

$$
d P_{t} / P_{t}=\mu d t+\sigma d Z_{t}
$$

Where, $P_{t}$ is the price of an asset, $d P_{t} / P_{t}$ is the instantaneous rate of return on an asset, $\mu$ and $\sigma$ are drift term and standard deviation of an asset respectively, and $d Z_{t}$ are a standardized Winner Process. It is also assumed that the return on assets follows the normal distribution of mean value $\mu-\sigma^{2} / 2$ with standard deviation of $\sigma$. In this study, discontinuous jumps in the rate of return on assets are taken into account, and it is assumed that the behavior of the rate of return obeys the random process of discrete Poisson jump diffusion, as shown in the following Equation (2):

$$
d P_{t} / P_{t}=\mu d t+\sigma d Z_{t}+\sum_{k=1}^{n_{t}} \pi_{k}
$$

Where $n_{t}$ is the discrete counting process that controls the number of jumps and is subject to the time-varying Poisson distribution, namely $n_{t} \sim \operatorname{Poisson}\left(\lambda_{t} d t\right)$, which is assumed to be independent of $d Z_{t}$, and $\lambda_{t}$ is the parameter of the Poisson distribution and $\lambda_{t}>0$, called Jump intensity, which represents the number of jumps caused by abnormal information in unit time $[\mathrm{t}, \mathrm{t}+d t]$. Therefore, when $n_{t}=j$, it represents the assumption that the asset has j jumps per unit time $[\mathrm{t}, \mathrm{t}+] . \pi_{k}$ reflects the instantaneous jump in asset returns caused by abnormal market information in the market, which is called jump size, and follows the normal distribution with the mean value of $\theta$ and the standard deviation of $\delta$, namely $\pi_{k} \sim N\left(\theta, \delta^{2}\right)$.

Bates (1991) believes that the market jump probability may change over time, so the research directions in recent years have set the conditional intensity to have the characteristics of changing with time. For example, Das (1998) and Fortune (1999) adopted dummy variables to set the jump intensity to change over time; Eraker (2004) and Kaeck and Alexander (2013) set the rate of return and volatility as the behavior of jumping. Chan and Maheu (2002) and Byun, Jeon, Min and Yoon(2015) set the jump intensity as the ARMA process, considered the GARCH effect of the return on assets, and named this model as ARJI. The model is expressed as follows:

$$
\begin{aligned}
& R_{t}=\mu+\sum_{i=1}^{n} \phi_{i} R_{t-i}+\sqrt{h_{t}} Z_{t}+\sum_{k=1}^{N_{t}} \pi_{t, k} \\
& h_{t}=\omega+\sum_{i=1}^{q} \alpha_{i} \varepsilon_{t-i}^{2}+\sum_{i=1}^{p} \beta_{i} h_{t-1} \\
& Z_{t} \sim \operatorname{NID}(0,1) \quad \pi_{t, k} \sim N\left(\theta_{t}, \delta^{2}\right) \quad N_{t} \sim \operatorname{Poisson}\left(\lambda_{t} d t\right)
\end{aligned}
$$




$$
\lambda_{t}=\lambda_{0}+\sum_{i=1}^{r} \rho_{i} \lambda_{t-i}+\sum_{i=1}^{s} \gamma_{i} \xi_{t-i}
$$

Where is the conditional variance equation of, which obeys the GARCH (p, q) process. $\varepsilon_{t}=R_{t}-\mu-\sum_{i=1}^{n} \phi_{i} R_{t-i}$ is the error term of the conditional mean equation. It is a standardized Wiener process. Assume that the jump size $\pi_{t, k}$ is independent of the standardized Wiener process. The jump size obeys the normal distribution of mean value $\theta_{t}$ and variance $\delta^{2} . \lambda_{t}$ is the jump intensity or jump frequency. Chan and Maheu (2002) defined $\lambda_{t}=\mathrm{E}\left[\mathrm{n}_{t} \mid \Omega_{t-1}\right]$, which means that the jump intensity is a conditional expected value that varies with time and obeys $\operatorname{ARMA}(\mathrm{r}, \mathrm{s})$ process, denote it as $\lambda_{t}=\lambda_{0}+\sum_{i=1}^{r} \rho_{i} \lambda_{t-i}+\sum_{i=1}^{s} \gamma_{i} \xi_{t-i}$, where $\lambda_{0}>0, \rho_{i}>\gamma_{i}, \gamma_{i}>0$ and $\lambda_{t-i}$ is the posterior probability. $\xi_{t-i}$ is the jump intensity error term, and $\xi_{t-i}$ is defined as:

$$
\begin{aligned}
\zeta_{t-i} & =E\left[n_{t-i} \mid \Phi_{t-1}\right]-\lambda_{t-i} \\
& =\sum_{j=0}^{\infty} j P\left(n_{t-i}=j \| \Phi_{t-1}\right)-\lambda_{t-i}
\end{aligned}
$$

Where $P\left(n_{t-i}=j \| \Phi_{t-i}\right)$ is the post evaluation of the expected number of jumps from t-i-1 to t-i, and $\lambda_{t-i}$ is the expected number of jumps in the information set $\Omega_{t-i-1}$. Under the known information set $\Omega_{t-i-1}, \zeta_{t-i}$ is the influencing factor that cannot predict the conditional mean of $n_{t-i}$, and conforms to the Martingale difference sequence, $E\left[\zeta_{t}\right]=0$ and $\operatorname{Cov}\left(\zeta_{t}, \zeta_{t-i}\right)=0, i>0$. Therefore, the error term of jump intensity does not have the nature of sequence or serial correlation. The unconditional jump intensity will be expressed as:

$$
E\left[\lambda_{t}\right]=\frac{\lambda_{0}}{1-\sum_{i=1}^{r} \rho_{i}}
$$

The intertemporal prediction of jump intensity can be expressed as the following equation (8):

$$
E\left[\lambda_{t} \mid \Omega_{t-1}\right] \mid=\left\{\begin{array}{l}
\lambda_{t} \\
\lambda_{0}+\sum_{j=0}^{i-1} \rho_{i}+\rho^{i} \lambda_{t}
\end{array}\right.
$$

In the Poisson distribution, $\lambda_{t}$ must be a positive value. In the case of $r=s$, the ARJI model can be re-expressed as follows:

$$
\lambda_{t}=\lambda_{0}+\sum_{i=1}^{r}\left(\rho_{i}-\gamma_{i}\right) \lambda_{t-i}+\sum_{i=1}^{r} \gamma_{i} E\left[N_{t-i} \Omega_{t-i}\right]
$$


Where for all $\mathrm{t}, \lambda_{t}>0$.

Let $f\left(R_{t} \mid n_{t}=j, \Phi_{t-1}\right)$ be the probability density function of the return under $\mathrm{j}$ jumps and the information set $\Omega_{t-1}$, so after obtaining information for period t-1, according to Bayes' theorem, the ex post probability of $\mathrm{j}$ jumps in period $\mathrm{t}$ can be estimated as (Maheu and McCurdy, 2004):

$$
P\left(n_{t}=j \mid \Phi_{t}\right)=\frac{f\left(R_{t} \mid n_{t}=j, \Phi_{t-1}\right) P\left(n_{t}=j \mid \Phi_{t-1}\right)}{P\left(R_{t} \mid \Phi_{t-1}\right)}
$$

Where $f\left(R_{t} \mid n_{t}=j, \Phi_{t-1}\right)$ is the normal conditional probability density function.

The probability density function of the normal condition when the rate of return contains $\mathrm{j}$ jumps in the unit interval can be expressed as follows:

$$
f\left(R_{t} \mid n_{t}=j, \Phi_{t-1}\right)=\frac{1}{\sqrt{2 \pi\left(h_{t}+j \delta_{t}^{2}\right)}} * \exp \left(-\frac{\left(R_{t}-\mu-\sum_{i=1}^{n} \phi_{i} R_{t-i}-\theta_{t} j\right)^{2}}{2\left(h_{t}+j \delta^{2}\right)}\right)
$$

The jump size is captured by $Y_{t j}$, and the parameter $Y_{t j}$ of $\left(\theta_{t}, \delta_{t}^{2}\right)$ can be used to explain the jump size distribution. Among them, $\psi=\left(\mu, \phi_{i}, \omega, \alpha_{j}, \beta_{i}, \theta, \delta, \lambda_{0}, \rho, \gamma\right)$ is the parameter vector to be estimated. Under the above settings, the log-likelihood function can be expressed as equation (12):

$$
L(\psi)=\sum_{t=1}^{T} \log f\left(R_{t} \mid \Omega_{t-1} ; \psi\right)
$$

Where $\psi$ represents all unknown parameters to be estimated and $\mathrm{T}$ is the number of samples.

According to the generalized conditions, the MLE value is subject to the asymptotic normal distribution. In this study, an iterative procedure is used to estimate the parameters and set a tolerance level until the final estimated value enters the error range and reaches convergence. Bollerslev (1986) suggested use the BHHH estimation method developed by Berndt, Hall, Hall and Hausman (1974) of QMLE for model estimation to obtain effective estimation results.

\section{Empirical Results and Analysis}

This section first discusses the construction and empirical analysis of the interaction model between S\&P500 stock index, its futures and NASDAQ index futures. Then, we further points out the results of the optimal hedging ratio and hedging performance. 


\subsection{Data Source and Processing}

In this study, regarding the selection of research variables, S\&P500 index futures are stock index futures contracts traded on Chicago Mercantile Exchange (CME), and are the most popular index futures traded in the U.S. market. We also use NASDAQ index futures that emphasize high-tech stocks to see their cross-hedging performance. This study selects daily data of these three market stock index to explore the interactions of these three market stock index returns and the phenomenon of volatility spillovers and jumps. This study selects daily data of these three market stock index to explore the interactions of these three market stock returns and the phenomenon of volatility spillovers and jumps. The data used for this study are from January 1, 2005 to August 31, 2018 for US S\&P500 stock index cash and futures and NASDAQ index futures to estimate related models. In general, what stock market investors really care about is the stock price return instead of daily closing prices. Therefore, in this study, the original prices of stock index for the markets is $P_{i, t}$. After taking the natural logarithm, it becomes $\ln P_{i, t}$, and the daily stock price return rate is $R_{i, t}=\left(\ln P_{i, t}-\ln P_{i, t-1}\right) \times 100, P_{i, t}$ is the closing stock index $i$ on date $t$, and $R_{\tilde{i}, t}$ is the stock index return.

\subsection{Data Descriptions and Unit-Root Test}

\subsubsection{Data Descriptions}

According to Table 1, it can be found that the average return rates of stock index in the three markets (S\&P500 stock index cash and futures and NASDAQ stock index futures) are all positive. The standard deviation show that the stock index return risk of NASDAQ index futures is the largest, followed by S\&P500 index futures, and the S\&P500 index cash is the smallest. The skewness coefficient shows that the S\&P500 index futures return rate presents an asymmetric left-biased distribution. According to the results that the kurtosis coefficients of the stock index returns of the three markets are all greater than 3 at a significant level of $1 \%$, it is found that the returns of these three stock index all present a state of leptokurtic distribution. The Jarque-Bera normal distribution test value (J-B value) shows that the return rate of each stock index does not follow the normal distribution at the significant level of $1 \%$. The above phenomenon also can infer that the return rate of each stock index cash and futures has a discontinuous jump effect.

According to the statistical value of Ljung-Box Q, each stock index return has a first-order serial correlation phenomenon at a significant level of $1 \%$. In this study, according to LJung-Box Q test, there is a first-order serial correlation between the return rates of all these three stock index at a significant level of $1 \%$. In this study, the LJung-Box Q test and the ARCH-LM test are used to analyze the returns of these three stock index and verify whether the data has ARCH phenomenon. Under the significant level of $1 \%$, all the stock index returns have second-order serial correlation phenomenon, which reflects the fact that the second-order dynamic difference of the stock index returns has serial correlation, that is, the stock price index returns have heterogeneous variation phenomenon that changes with time. It can be seen from 
the above results that these three stock price index returns all have the characteristics of conditional heterogeneous variance proposed by Engle (1982). Bollerslev (1986) believed that conditional variance is an ARMA process, so the traditional ARCH model was further expanded to form the GARCH model.

This research considers the volatility clustering, volatility persistence, and instantaneous jumps in financial time series data. In order to fully capture the fluctuation characteristics of the return rate of these financial time series data and the discontinuous or instantaneous jump or jump-diffusion phenomenon, follow-up will use ARJI-GARCH or its extended model for empirical analysis in this study.

Table 1: Descriptive Statistics for the Returns of S\&P500 Index Cash and Futures and NASDAQ Index Futures

\begin{tabular}{llll}
\hline & $\begin{array}{l}\text { S\&P500 Index Cash } \\
\left(\mathrm{R}_{\mathrm{c}}\right)\end{array}$ & $\begin{array}{l}\text { S\&P500 Index Futures } \\
\left(\mathrm{R}_{\mathrm{f}}\right)\end{array}$ & $\begin{array}{l}\text { NASDAQ Index } \\
\text { Futures }\left(\mathrm{R}_{\mathrm{N}}\right)\end{array}$ \\
\hline Mean & 0.000814 & 0.000844 & 0.000101 \\
Median & 0.000783 & 0.000772 & 0.000627 \\
Maximum & 0.109572 & 0.132022 & 0.127480 \\
Minimum & -0.094695 & -0.104003 & -0.096122 \\
Std. Dev. & 0.014169 & 0.014261 & 0.013101 \\
Skewness & -0.292399 & -0.077327 & 0.298406 \\
Kurtosis & 12.39822 & 15.21892 & 17.55576 \\
J-B value & $7134.124^{* * *}$ & $12033.26^{* * * *}$ & $17110.74^{* * *}$ \\
Q(10) & $53.007 * * *$ & $52.15 * * *$ & $67.281^{* * *}$ \\
$\mathrm{Q}^{2}(12)$ & $32615.3157^{* * *}$ & $32304.4120^{* * *}$ & $33414.2506^{* * *}$ \\
ARCH-LM & $392.7152^{* * *}$ & $372.6241^{* * *}$ & $404.25^{* * * *}$ \\
\hline
\end{tabular}

Note: $1 .{ }^{* * *}, * *$ and $*$ denote the significant at the $1 \%, 5 \%$ and $10 \%$ level, respectively. $2 . Q^{2}$ is the test of $\mathrm{Q}$ after the series is squared

\subsubsection{Unit-Root and Co-integration Tests}

\section{(1) Unit-Root Tests}

Before the follow-up empirical analysis, a unit root test is used to determine the integrated order of the financial time series to be studied in this research, and to determine whether the nature of the time series is stationary, so as to avoid false statistical inferences caused by spurious regression phenomenon in the empirical analysis. The results of ADF unit root tests using three models with intercept, with intercept and time trend, and without intercept and time trend are listed below.

Table 2 shows the ADF unit-root test results of the original series (after taking the natural logarithm) of three stock index and the series of index returns of cash and futures. According to Table 2, when selecting the optimal lag period by AIC criterion, the original series of the three stock indexes in the ADF unit-root tests cannot reject the null hypothesis that there is a unit root phenomenon, that is, the original 
series data of the three stock indexes are all non-stationary. Therefore, in this study, all original stock price index series are converted into a return rate pattern by first-order difference, then the ADF unit-root test is performed again. Under three unit-root test models, it is found that the return series of the three stock index returns reject the null hypothesis with a unit root phenomenon at the significant level of $1 \%$. It means that all stock index return series have conformed to the nature of stationary series, that is, the original index series all have the same integrated order I (1) level.

Table 2: Results of Unit Root Tests

\begin{tabular}{lllll}
\hline \multicolumn{5}{c}{ ADF Unit Root Tests } \\
\hline & With Intercept & $\begin{array}{l}\text { With Intercept and } \\
\text { Trend Term }\end{array}$ & $\begin{array}{l}\text { Without Intercept } \\
\text { and Trend Term }\end{array}$ \\
\hline Original Series & $\mathrm{c}$ & $-2.2145[4]$ & $-2.2154[4]$ & $0.8425[4]$ \\
(After taking the & $\mathrm{f}$ & $-2.2417[2]$ & $-2.2315[2]$ & $0.8115[2]$ \\
natural logarithm) & $\mathrm{N}$ & $-1.7103[1]$ & $-1.8532[1]$ & $0.8132[1]$ \\
\hline Return Rates Series & $\mathrm{R}_{\mathrm{c}}$ & $-54.7345^{* * *[5]}$ & $-54.8182^{* * *[5]}$ & $-54.8213^{* * *[5]}$ \\
& $\mathrm{R}_{\mathrm{f}}$ & $-54.7089^{* * *[3]}$ & $-54.7866^{* * *[3]}$ & $-54.7032^{* * *[3]}$ \\
& $\mathrm{R}_{\mathrm{n}}$ & $-42.3012^{* * *[2]}$ & $-42.3421^{* * *[2]}$ & $-42.2134 * *[2]$ \\
\hline
\end{tabular}

Note: 1. $\mathbf{c}$ denotes S\&P500 index cash, $\mathbf{f}$ denotes S\&P500 index futures and N denotes NASDAQ index futures

2. The values in [.] are the most fitting lags determined by the Akaike information criterion (AIC).

3. $* * *, * *$ and $*$ denote the significant at the $1 \%, 5 \%$ and $10 \%$ level, respectively.

\section{(2) Johansen's Co-integration Tests}

According to the aforementioned unit-root test results, the time series after the natural logarithm transformation of the three market stock index is also I(1), with the same integration order, and there may be a long-term co-integration relationship between the series. These stock indexes are used for co-integration analysis. If there is a co-integration relationship, the linear combination of each variable can be converted into a stationary series, and it is not necessary to make a difference so as to avoid the loss of long-term equilibrium relationship due to difference. This study uses the Trace and Max-eigenvalue test proposed by Johansen to determine the number of co-integration vectors, and then uses the maximum likelihood estimation (MLE) method to estimate the parameters of the co-integration vectors. According to the test results in Table 3, the null hypothesis that the number of co-integration vectors is zero is rejected, and the null hypothesis that the number of co-integration vectors is one is accepted. This means that there is a long-term co-integration relationship between the time series after the natural logarithm transformation of these three stock indexes(S\&P500 stock index cash and futures and NASDAQ stock index futures). The co-integration relationship means that each market may have its own different fluctuations in a short period of time, but the long-term stock price trend is driven by the mutual influence of each market to drive other stock markets to form a co-movement trend phenomenon. 
Table 3: Johansen Co-integration Tests

\begin{tabular}{|c|c|c|c|}
\hline \multicolumn{4}{|c|}{ Trace Test } \\
\hline Hypothesized & Eigenvalue & Trace Statistic & $5 \%$ Critical Value \\
\hline None $* *$ & 0.0621 & 173.902 & 36.203 \\
\hline At most 1 & 0.0034 & 9.9872 & 21.275 \\
\hline At most 2 & 0.0010 & 2.2432 & 9.274 \\
\hline \multicolumn{4}{|c|}{ Maximum Eigenvalue Test } \\
\hline Hypothesized & Eigenvalue & Max-Eigen Statistic & $5 \%$ Critical Value \\
\hline None $* *$ & 0.05831 & 154.1125 & 22.29962 \\
\hline At most 1 & 0.0032 & 8.5432 & 15.89210 \\
\hline At most 2 & 0.0009 & 2.6715 & 9.164546 \\
\hline $\operatorname{Ln}\left(\mathrm{c}_{t}\right)$ & $\operatorname{Ln}\left(f_{t}\right)$ & $\operatorname{Ln}\left(\mathrm{N}_{\mathrm{t}}\right)$ & $\mathrm{C}$ \\
\hline \multirow[t]{2}{*}{1.000000} & $-1.0102 * * *$ & $0.005123 * * *$ & $-0.0315 * * *$ \\
\hline & $(2.8142)$ & $(2.4124)$ & $(2.6742)$ \\
\hline
\end{tabular}

Note : $* * *$ and $* *$ denote statistical significance at the $1 \%$ and $5 \%$ levels, respectively.

Based on the results obtained above Table 3, a set of error correction terms (ECT) is established as follows:

$$
Z_{t}=\operatorname{Ln}\left(c_{t}\right)-1.0102 \operatorname{Ln}\left(\mathrm{f}_{\mathrm{t}}\right)+0.005123 \operatorname{Ln}\left(\mathrm{N}_{\mathrm{t}}\right)-0.0315
$$

According to the results of the previous Johansen co-integration test, it can be found that there is indeed a long-term equilibrium co-integration relationship between the S\&P500 stock price index cash and futures and the NASDAQ index futures three markets, and there is an obvious set of co-integration vectors. Therefore, this study will use the VEC (vector error correction) model to further explore the longand short-term dynamic adjustment process between the three markets. This article first constructs the VEC model of the three-market stock index return lagging by $\mathrm{n}$ periods, and according to the above-mentioned financial time series data of the three markets, the index return has a discontinuous or instantaneous jump or jump-diffusion phenomenon, In other words, the fluctuation of asset return rate is not continuous, and it will cause discontinuous jump phenomenon due to the impact of new information. That is to say, this study intends to adopt the ARJI model proposed by Chan and Maheu (2002) in Section II, and set its conditional jump intensity as a characteristic that changes with time and conform to the ARMA form of ARJI-VEC econometric model for further relevant analysis.

\subsection{ARJI-VEC Model Setups, Tests for Series Correlation, ARCH and Asymmetry Effect of Residual Terms}

Under the rate of return for these three stock indexes as an information set, the ARJI-VEC model of this study is set as follows: 


\section{ARJI-VEC Model}

$$
\begin{aligned}
& R_{c, t}=\mu_{1}+\gamma_{1} z_{t-1}+\sum_{i=1}^{n} \phi_{i} R_{c, t-i}+\sum_{i=1}^{n} \kappa_{i} R_{\mathrm{f}, t-i}+\sum_{i=1}^{n} l_{i} R_{N, t-i}+\varepsilon_{c, t}+J_{c, t} \\
& R_{f, t}=\mu_{2}+\gamma_{2} z_{t-1}+\sum_{i=1}^{n} b_{i} R_{f, t-i}+\sum_{i=1}^{n} \varsigma_{i} R_{c, t-i}+\sum_{i=1}^{n} j_{i} R_{N, t-i}+\varepsilon_{f, t}+J_{f, t} \\
& R_{N, t}=\mu_{3}+\gamma_{3} z_{t-1}+\sum_{i=1}^{n} m_{i} R_{N, t-i}+\sum_{i=1}^{n} p_{i} R_{c, t-i}+\sum_{i=1}^{n} o_{i} R_{f, t-i}+\varepsilon_{N, t}+J_{N, t}
\end{aligned}
$$

Where $R_{c, t}, R_{f, t}, R_{N, t}$ represent return rates of S\&P500 index cash, futures and NASDAQ index futures at time $\mathrm{t}$, respectively. $Z_{t-1}$ is the error correction term. $\varepsilon_{c, t}, \varepsilon_{f, t}, \varepsilon_{N, t}$ represents the normal random disturbances or residuals and are independent of $J_{t}$ (jump component). Each event $\left(J_{t}\right)$ is also independent of each other. $J_{t}$ is a jump component, used to capture the phenomenon of excess kurtosis of return. $J_{t}$ is the actual jump size $\left(\mathrm{Y}_{\mathrm{t}}\right)$ minus the expected jump size, which reflects the jump in return fluctuations caused by abnormal information.

$$
J_{t, i}=\sum_{j=0}^{n_{t}} Y_{t j i}-E\left(\sum_{j=0}^{n_{t}} Y_{t j i}\right) \quad i=c, f, N
$$

Where, $Y_{t} \sim N\left(\theta_{t}, \delta_{t}^{2}\right)$ is the jump size that varies with time. Jump size refers to the phenomenon of instantaneous jump diffusion of returns on assets caused by unusual market information (caused by unexpected special events). $n_{t}$ is the number of jumps at $[\mathrm{t}-1, \mathrm{t}]$, and

$$
P\left(n_{t}=J \mid \Omega_{t-1}\right)=\frac{e^{-\lambda_{t}} \lambda_{t}}{j !}, j=1,2, \ldots
$$

Where $\lambda_{t}$ is the Poission distribution subject to the average number of jumps. And

$\Omega_{t-1}$ is the information set at time $\mathrm{t}-1$. When $n_{t}=J$, it means that the asset return has $J$ jumps per unit time $[t-1, t]$, and the frequency of occurrence is governed by the parameter $\lambda_{t}$ (jump intensity). In the Poisson distribution, both mean and variance are $\lambda_{t}$, the so-called jump intensity, i.e., the average number of events occurring in a time interval. Events refer to new information shocks that can cause abnormal price fluctuations (Maheu and McCurdy, 2004). Here, we define $\lambda_{t}=\mathrm{E}\left[\mathrm{n}_{t} \mid \Omega_{t-1}\right]$ as the expected number of jumps under rate of return for these three stock indexes as an information set $\Omega_{t-1}$. In this study, it is set to follow an endogenous $\operatorname{ARMA}(1,1)$ process, which is expressed as follows:

$$
\lambda_{t i}=\lambda_{0 i}+\lambda_{1 i} \lambda_{i t-1}+\lambda_{2 i} \xi_{i t-1} \quad i=c, f, N
$$


Where $\lambda_{0}>0, \lambda_{1}>\lambda_{2}, \lambda_{2}>0 . \lambda_{t-1}$ is the ex post probability; $\xi_{t-1}$ is the jump intensity error term, which is used to capture the number of unexpected jumps in the previous period, and it is defined as:

$$
\begin{aligned}
\xi_{t-1} & =E\left[n_{t-1} \mid \Phi_{t-1}\right]-\lambda_{t-1} \\
& =\sum_{j=0}^{\infty} j P\left(n_{t-1}=j \| \Phi_{t-1}\right)-\lambda_{t-1}
\end{aligned}
$$

Where $P\left(n_{t-1}=j \| \Phi_{t-1}\right)$ is called filter to infer ex Post probability of $n_{t-1}$ at time t-1. $E\left[n_{t-i} \mid \Phi_{t-1}\right]$ is the ex post evaluation of the expected number of jumps from $t-i-1$ to $t-i$, and $\lambda_{t-1}$ is the expected number of jumps under the information set $\Omega_{t-i-1}$. Under the known information set $\Omega_{t-i-1}$, $\xi_{t-1}$ is the unpredictable influencing factor for the inference of conditional mean and accords with the martingale difference sequence, $E\left[\xi_{t}\right]=0$ and $\operatorname{Cov}\left(\xi_{t}, \xi_{t-i}\right)=0, i>0$, Therefore, the error term of jump intensity does not have the property of sequence (serial) correlation.

Let $f\left(R_{t} \mid n_{t}=j, \Phi_{t-1}\right)$ be the probability density function of the stock returns $R_{t}$ in the case of $J$ jumps and information set $\Omega_{t-1}$. Therefore, Chan and Maheu (2002) used rule Bayes' rule to estimate the ex post probability of $J$ jumps occurring in time $\mathrm{t}$ after obtaining information in period $\mathrm{t}-1$, and defined the filter as:

$$
P\left(n_{t}=j \mid \Phi_{t}\right)=\frac{f\left(R_{t} \mid n_{t}=j, \Phi_{t-1}\right) P\left(n_{t}=j \mid \Phi_{t-1}\right)}{P\left(R_{t} \mid \Phi_{t-1}\right)}
$$

$P\left(n_{t}=j \mid \Phi_{t}\right)$ can be obtained from equation (18). In the equation (18), the filter is a very important factor in dynamic jumping. It can be used for prediction. For example, the probability of at least one jump occurring is $1-P\left(n_{t}=0 \mid \Phi_{t-1}\right)$. Where $f\left(R_{i t} \mid n_{t}=j, \Phi_{t-1}\right)$ is the conditional probability density function with assumed normality such as:

$$
\begin{aligned}
& f\left(R_{c t} \mid n_{t}=j, \Phi_{t-1}\right)=\frac{1}{\sqrt{2 \pi\left(h_{c t}+j \delta_{c t}^{2}\right)}} * \exp \left(-\frac{\left(R_{t, c}-\mu_{1}+\sum_{i=1}^{n} \phi_{i} R_{t-i, \mathrm{c}}+\sum_{i=1}^{n} \kappa_{i} R_{t-i, \mathrm{f}}+\sum_{i=1}^{n} l_{i} R_{t-i, \mathrm{~N}}-\theta_{c t} j\right)^{2}}{2\left(h_{c t}+j \delta_{c t}^{2}\right)}\right) \\
& f\left(R_{f t} \mid n_{t}=j, \Phi_{t-1}\right)=\frac{1}{\sqrt{2 \pi\left(h_{f t}+j \delta_{f t}^{2}\right)}} * \exp \left(-\frac{\left(R_{t, \mathrm{f}}-\mu_{2}+\sum_{i=1}^{n} b_{i} R_{t-i, \mathrm{f}}+\sum_{i=1}^{n} \varsigma_{i} R_{t-i, \mathrm{c}}+\sum_{i=1}^{n} j_{i} R_{t-i, \mathrm{~N}}-\theta_{f t} j\right)^{2}}{2\left(h_{f t}+j \delta_{f t}^{2}\right)}\right)
\end{aligned}
$$




$$
f\left(R_{N t} \mid n_{t}=j, \Phi_{t-1}\right)=\frac{1}{\sqrt{2 \pi\left(h_{N t}+j \delta_{N t}^{2}\right)}} * \exp \left(-\frac{\left(R_{t, \mathrm{~N}}-\mu_{3}+\sum_{i=1}^{n} m_{i} R_{t-i, \mathrm{~N}}+\sum_{i=1}^{n} p_{i} R_{t-i, \mathrm{c}}+\sum_{i=1}^{n} o_{i} R_{t-i, \mathrm{f}}-\theta_{N t} j\right)^{2}}{2\left(h_{N t}+j \delta_{N t}^{2}\right)}\right)
$$

After integrating all jumps in the unit interval, the conditional probability density function of stock index return can be expressed as follows:

$$
P\left(R_{t} \mid \Omega_{t-1}\right)=\sum_{i=0}^{\infty} f\left(R_{t} \mid n_{t}=j, \Omega_{t-1}\right) P\left(n_{t}=j \mid \Omega_{t}\right)
$$

Let $\psi=\left(\mu_{\tilde{i}}, \phi_{i}, k_{i}, l_{\tilde{i}}, b_{i}, \varsigma_{\tilde{i}}, j_{i}, m_{i}, p_{i}, o_{i}, \gamma_{1}, \omega_{i}, \alpha_{i}, \beta_{i}, \theta_{i}, \delta_{i}, \delta, \lambda i_{0}, \lambda i_{1}, \lambda i_{2}\right)$ be the parameter to be estimated in this study and under the above setting, the logarithmic likelihood function can be expressed as:

$$
L(\psi)=\sum_{t=1}^{T} \log f\left(R_{t} \mid \Omega_{t-1} ; \psi\right)
$$

Based on the foregoing, this study uses Johansen's MLE method to estimate the co-integration relationship among variables. Johansen co-integration analysis is based on the vector autoregressive model (VAR). Therefore, the optimal number of lagging periods for the VAR model must be determined first, and the optimal number of lagging periods is selected with AIC as the minimum value of lag periods. According to the test results as shown in Table 4, after the three stock index return is estimated by the VAR model, the number of lagging periods with the smallest AIC values is 5 periods. Therefore, this study selects the optimal number of lag periods as 5 as the estimation basis of the VEC-ARJI measurement model, and uses the aforementioned BHHH algorithm to calculate relevant parameters and estimate residual terms through WinRATE8.0 to determine whether this study will further consider the corresponding model with ARCH and information asymmetry effects.

Table 4: Selection of Optimal Lag Periods of VAR Model for These Three Index Markets by AIC

\begin{tabular}{cccc}
\hline & $\operatorname{Ln}\left(\mathrm{c}_{t}\right)$ & $\operatorname{Ln}\left(\mathrm{f}_{\mathrm{t}}\right)$ & $\operatorname{Ln}\left(\mathrm{N}_{\mathrm{t}}\right)$ \\
\hline $\mathrm{Lag}$ & $\mathrm{AIC}$ & $\mathrm{AIC}$ & $\mathrm{AIC}$ \\
\hline 2 & 7.936433 & 7.992702 & 10.5857 \\
& & & \\
3 & 7.936401 & 7.992403 & 10.58513 \\
& & & 10.59622 \\
4 & 7.937268 & 7.992303 & 10.59634 \\
\hline \hline
\end{tabular}




\begin{tabular}{cccc}
\hline \hline 5 & $7.936104 \#$ & $7.992043 \#$ & $10.596205 \#$ \\
6 & 7.936171 & 7.992281 & 10.59649 \\
7 & 7.936462 & 7.992342 & 10.59656 \\
8 & 7.936513 & 7.992445 & 10.60667
\end{tabular}

Note: \# represents the one with the smallest AIC value, which is the optimal number of lag periods

According to the estimation results of the ARJI-VEC model in Table 5, the Ljung-Box Q test of the estimated standardized residuals $\left(Z_{c, t}, Z_{\mathrm{f}, t}\right.$ and $\left.Z_{\mathrm{N}, t}\right)$ of the model shows that the estimated standardized residuals of the ARJI -VEC model after matching the time series of the three market index returns conform to the null hypothesis of no serial correlation. Therefore, it can be determined that each market index not only has the same integration order, but also conforms to no serial correlation.

Table 5: Serial Correlation, ARCH and Asymmetric Effect Tests on Standardized Residuals Terms for Estimated ARJI-VEC Model

\begin{tabular}{llll}
\hline & $Z_{c, t}=\hat{\varepsilon}_{c, t} / \sqrt{h_{c, t}}$ & $Z_{\mathrm{f}, t}=\hat{\varepsilon}_{\mathrm{f}, t} / \sqrt{h_{\mathrm{f}, t}}$ & $Z_{\mathrm{N}, t}=\hat{\varepsilon}_{\mathrm{N}, t} / \sqrt{h_{\mathrm{N}, t}}$ \\
\hline $\mathrm{Q}(12)$ & 12.3152 & 10.0732 & 8.1562 \\
$\mathrm{Q}(18)$ & 16.3142 & 18.1256 & 11.4009 \\
\hline & $Z_{c, t}{ }^{2}$ & $Z_{\mathrm{f}, t}{ }^{2}$ & $Z_{\mathrm{N}, t}{ }^{2}$ \\
\hline $\mathrm{Q}(12)$ & $511.1129 * * *$ & $514.7702 * * *$ & $955.0009 * * *$ \\
$\mathrm{Q}(18)$ & $703.1188 * * *$ & $704.9124 * * *$ & $1393.0005 * * *$ \\
\hline & $Z_{c, t} Z_{\mathrm{f}, t}$ & $Z_{c, t} Z_{\mathrm{N}, t}$ & $Z_{\mathrm{f}, t} Z_{\mathrm{N}, t}$ \\
\hline$Q(12)$ & $113.6286 * * *$ & $123.0208 * * *$ & $124.0568 * * *$ \\
$Q(18)$ & $214.9783 * * *$ & $215.9432 * * *$ & $217.5242 * * *$ \\
\hline $\mathrm{SBT}$ & $Z_{c, t}$ & $Z_{\mathrm{f}, t}$ & $Z_{\mathrm{N}, t}$ \\
$\mathrm{NSPT}$ & $15.7125 * * *$ & $11.3678 * * *$ & $11.5526 * * *$ \\
PSBT & $17.7152 * * *$ & $10.7825 * * *$ & $15.1125 * * *$ \\
$\mathrm{JT}$ & 0.9128 & 0.9932 & $6.0031 * *$ \\
\hline
\end{tabular}

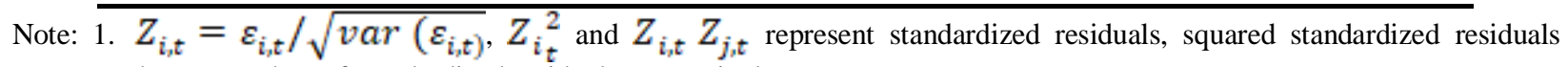
and cross-product of standardized residuals, respectively.

2. SBT, NSBT, PSBT are tested by t-values, and JT is by F-value.

3. ${ }^{* * *}, * *$ and $*$ denote the significant at the $1 \%, 5 \%$ and $10 \%$ level, respectively. 
In terms of the Ljung-Box $Q$ test $(\mathrm{Q}(12), \mathrm{Q}(18))$ for estimating the squares of standardized residuals from ARJI-VEC model we set up, it can be found that none of the squares of the standardized residuals and cross-product of the two standardized residuals of the three-market mean equations can pass the serial correlation test, i.e., the serial correlation exists in the squared standardized residuals $\left(\mathrm{Z}_{c, t}^{2}\right.$,

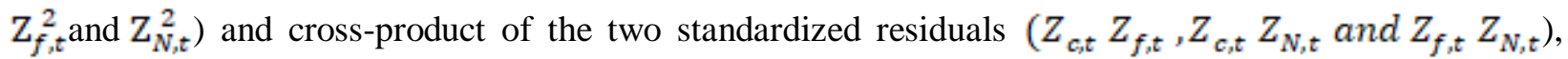
that is the presences of ARCH effects in the residuals in our model system which means that the squares of the standardized residuals have serial correlation, that is, all have obvious ARCH effects in ARJI-VEC model. This result shows that the variance of the stock index return has the characteristics of conditional heteroscedasticity. Therefore, the GARCH related model in which the conditional variance changes over time should be considered to estimate the conditional heterogeneous variance. According to the results for testing asymmetric effects of the standardized residuals in Table 4, the related statistics for the sign bias test (SBT), negative sign bias test (NSBT), positive sign bias test (PSBT) and joint test (JT) are statistically significant for the standardized squared residuals. Therefore, it can be concluded that asymmetric properties of volatility do exist in these three stock markets, and then ARJI VEC GJR-GARCH model will be applied in this study.

\subsection{ARJI VEC GJR-GARCH model Setups and Empirical Result Analysis}

\subsubsection{ARJI VEC GJR-GARCH Model Setups}

\section{(1) Conditional Mean Equations}

$$
\begin{aligned}
& R_{c, t}=\mu_{1}+\gamma_{1} z_{t-1}+\sum_{i=1}^{n} \phi_{i} R_{c, t-i}+\sum_{i=1}^{n} \kappa_{i} R_{\mathrm{f}, t-i}+\sum_{i=1}^{n} l_{i} R_{N, t-i}+\varepsilon_{c, t}+J_{c, t} \\
& R_{f, t}=\mu_{2}+\gamma_{2} z_{t-1}+\sum_{i=1}^{n} b_{i} R_{f, t-i}+\sum_{i=1}^{n} \varsigma_{i} R_{c, t-i}+\sum_{i=1}^{n} j_{i} R_{N, t-i}+\varepsilon_{f, t}+J_{f, t} \\
& R_{N, t}=\mu_{3}+\gamma_{3} z_{t-1}+\sum_{i=1}^{n} m_{i} R_{N, t-i}+\sum_{i=1}^{n} p_{i} R_{c, t-i}+\sum_{i=1}^{n} o_{i} R_{f, t-i}+\varepsilon_{N, t}+J_{N, t}
\end{aligned}
$$

In the conditional mean equation, $J_{t}$ is the jump component and the related concepts of jump components and jump size (frequency or jump intensity, $\lambda_{t}$ ) can be seen in the aforementioned equations (13)-(21).

\section{(2) Conditional Variance Equations}

$$
\begin{aligned}
& h_{c, t}=w_{1}+\beta_{c} \varepsilon_{c, t-1}^{2}+\alpha_{c} h_{c, t-1}+f_{c f} h_{f, t-1}+g_{c N} h_{N, t-1}+\varphi_{1} S_{c, t-i}^{-} \varepsilon_{c, t-i}^{2} \\
& h_{f, t}=w_{2}+\beta_{f} \varepsilon_{f, t-1}^{2}+\alpha_{f} h_{f, t-1}+f_{f c} h_{c, t-1}+g_{f N} h_{N, t-1}+\varphi_{2} S_{f, t-i}^{-} \varepsilon_{f, t-i}^{2} \\
& h_{\mathrm{N}, t}=w_{3}+\beta_{N} \varepsilon_{N, t-1}^{2}+\alpha_{N} h_{N, t-1}+f_{N c} h_{c, t-1}+g_{N f} h_{f, t-1}+\varphi_{3} S_{N, t-i}^{-} \varepsilon_{N, t-i}^{2}
\end{aligned}
$$


The GJR-GARCH model uses dummy variables to distinguish the influence of positive (good) and negative (bad) information (news) on the conditional variance. When $\varepsilon_{\mathrm{t}-\mathrm{j}}<0$, then $\mathrm{S}_{\mathrm{t}-\mathrm{j}}^{-}=1$; when $\varepsilon_{\mathrm{t}-\mathrm{j}} \geq 0$, then $\mathrm{S}_{\mathrm{t}-\mathrm{j}}^{-}=0$.

\section{(3) Conditional Co-variance Equations}

$$
\begin{aligned}
& h_{c f, t}=N_{1,2}+m_{1,2} h_{c, f, t-1}+v_{1,2} \varepsilon_{c, t-1} \varepsilon_{f, t-1} \\
& h_{c N, t}=N_{1,3}+m_{1,3} h_{c, N, t-1}+v_{1,3} \varepsilon_{c, t-1} \varepsilon_{N, t-1} \\
& h_{f N, t}=N_{2,3}+m_{2,3} h_{f, N, t-1}+v_{2,3} \varepsilon_{f, t-1} \varepsilon_{N, t-1} \\
& \varepsilon_{t}=\left[\begin{array}{l}
\varepsilon_{1, t} \\
\varepsilon_{2, t} \\
\varepsilon_{3, t}
\end{array}\right] \quad \varepsilon_{t} \sim N\left(0, H_{t}\right) \quad H_{t}=\left[\begin{array}{lll}
h_{1, t} & h_{12, t} & h_{13, t} \\
h_{21, t} & h_{2, t} & h_{23, t} \\
h_{31, t} & h_{32, t} & h_{33, t}
\end{array}\right]
\end{aligned}
$$

Variables and Parameters can be defined as follows:

\section{Variables:}

$R_{c, t} \cdot R_{f, t} \cdot R_{N, t}$ : Return rates of S\&P500 index cash, futures and NASDAQ index futures at time $\mathrm{t}$, respective

$Z_{t-1}:$ Error correction term at time t-1

$\varepsilon_{c, t}, \varepsilon_{f, t}, \varepsilon_{N, t}$ : The residual terms of the spot exchange rate returns of Taiwan Hong Kong and Japan at time $t$ in conditional mean equation

$J_{c, t}, J_{f, t}, J_{N, t}$ : The jump components of the return rates of the S\&P500 stock index spot, futures and NASDAQ stock index futures at time $t$, respectively

$h_{c, t}, h_{f, t}, h_{N, t}:$ The conditional variances of the returns of S\&P500 index cash, futures and NASDAQ stock index futures at time t.

$h_{c f, t}, h_{c N, t}, h_{f N, t}:$ The conditional co-variances of the returns of S\&P500 index cash, futures and NASDAQ stock index futures at time $\mathrm{t}$.

\section{Parameters}

$\mu_{1}, \mu_{2}, \mu_{3}:$ Intercept terms in the three conditional mean equations of the S\&P500 index cash, futures and NASDAQ index futures markets

$\gamma_{1}, \gamma_{2}, \gamma_{3}:$ Measuring the adjustment speed of the returns in the S\&P500 index cash, futures and NASDAQ index futures markets towards the long-term equilibrium relationship

$\phi_{i}, \kappa_{i}, l_{i}, b_{i}, \varsigma_{i}, j_{i}, m_{i}, p_{i}, o_{i}$ : Measuring whether the returns of the S\&P500 index cash, futures and NASDAQ index futures markets have own- and cross-market spillover effects

$w_{1}, w_{2}, w_{3}$ : Intercept terms in the three conditional variance equations of the S\&P500 index cash, 
futures and NASDAQ index futures markets

$\beta_{c} \cdot \beta_{f}, \beta_{N}$ : Measuring whether the conditional variances of the returns have the ARCH effects in these three markets

$\alpha_{c}, \alpha_{f}, \alpha_{N}$ : Measuring whether the conditional variances of the returns have the GARCH effects in these three markets

$\varphi_{1}, \varphi_{2}, \varphi_{3}:$ Measuring the asymmetry effects of these three markets themselves

\subsubsection{Empirical Result Analysis}

\section{(1) Results of Conditional Mean Equations}

This study uses the conditional average equation in the ARJI VEC GJR-GARCH model to capture the behavior of the S\&P500 stock index cash, futures and NASDAQ stock index futures returns. Table 6 shows the estimated results of conditional mean equation in ARJI VEC GJR-GARCH model. Each of these effects is described below.

\section{A. Results and Analysis of Jumping Phenomena}

According to the estimation results of ARJI VEC GJR-GARCH model, $\lambda_{0}$ is positive in the three markets, indicating that the impact of unexpected events on the three markets increases the jump frequency. Furthermore, the jump parameters $\left(\lambda_{c 1}, \lambda_{f 1}, \lambda_{N 1}\right)$ of the three markets are all significant at the $1 \%$ significance level, showing that the jump frequency (jump frequency) is not a fixed constant during the estimation period (Bates, 1991), that is, the jump frequency generated by abnormal information changes with time, and the jump of the today is significantly affected by the jump of the previous day; Among them, the estimated parameter of NASDAQ stock index futures is the largest, indicating that the previous information has the most obvious influence on the return rate of NASDAQ stock index futures market. By observing the jump intensity $\left(\lambda_{0}+\lambda_{1}\right)$ of S\&P500 stock index futures and NASDAQ stock index

Table 6: Estimated Results of the Conditional Mean Equations

\begin{tabular}{ccccccccc}
\hline$R_{c, t}$ & Coeff & t-value & $R_{f, t}$ & Coeff & t-value & $R_{N, t}$ & Coeff & t-value \\
\hline$\mu_{1}$ & $5.42 \mathrm{e}-04$ & $2.9321 * * *$ & $\mu_{2}$ & $6.03 \mathrm{e}-04$ & $2.7154 * * *$ & $\mu_{3}$ & $7.38 \mathrm{e}-04$ & $2.8152 * * *$ \\
$\gamma_{1}$ & -0.0242 & $-2.2415 * * *$ & $\gamma_{2}$ & -0.0152 & $-1.9712 * *$ & $\gamma_{3}$ & -0.0452 & $-2.7142 * * *$ \\
$\phi_{1}$ & -0.4123 & $3.2157 * * *$ & $b_{1}$ & 0.0725 & 0.7238 & $m_{1}$ & 0.0928 & $1.9712 *$ \\
$\phi_{2}$ & 0.2375 & $2.3815 * *$ & $b_{2}$ & 0.1021 & $2.0124 * *$ & $m_{2}$ & 0.0008 & 0.0428 \\
$\phi_{3}$ & 0.0915 & 1.0345 & $b_{3}$ & 0.0415 & 0.4432 & $m_{3}$ & 0.0715 & 0.6025 \\
$\phi_{4}$ & 0.0415 & 1.5321 & $b_{4}$ & 0.0412 & $2.5415 * * *$ & $m_{4}$ & 0.0383 & $2.2452 * * *$
\end{tabular}




\begin{tabular}{ccccccccc}
$\phi_{5}$ & 0.0501 & $2.1821^{* *}$ & $b_{5}$ & 0.0425 & $2.2514 * *$ & $m_{5}$ & 0.0419 & 1.7125 \\
$\kappa_{1}$ & 0.3712 & $3.1521^{* * *}$ & $\varsigma_{1}$ & 0.0826 & 1.4215 & $p_{1}$ & 0.0932 & 0.7882 \\
$\kappa_{2}$ & 0.2351 & $2.6158^{* *}$ & $\varsigma_{2}$ & 0.0415 & $2.4125^{* *}$ & $p_{2}$ & 0.0715 & $2.0415^{* *}$ \\
$\kappa_{3}$ & 0.0728 & 0.9125 & $\varsigma_{3}$ & 0.0712 & 0.7321 & $p_{3}$ & 0.0712 & 0.5546 \\
$\kappa_{4}$ & 0.06108 & 0.9125 & $\varsigma_{4}$ & 0.0935 & $2.7136^{* * *}$ & $p_{4}$ & 0.0688 & $2.1465 * *$ \\
$\kappa_{5}$ & 0.0728 & 0.8812 & $\varsigma_{5}$ & 0.0625 & $2.2452^{* * *}$ & $p_{5}$ & 0.0623 & 0.6722 \\
$\boldsymbol{\iota}_{1}$ & 0.0045 & 0.2145 & $j_{1}$ & 0.0008 & 0.5412 & $o_{1}$ & 0.0304 & 0.9125 \\
$\boldsymbol{l}_{2}$ & 0.0202 & $2.0154^{* *}$ & $j_{2}$ & 0.1324 & $2.4675^{* *}$ & $o_{2}$ & 0.0703 & $2.2541^{* * *}$ \\
$\boldsymbol{l}_{3}$ & 0.0423 & 1.1621 & $j_{3}$ & 0.1158 & $2.3157^{* * *}$ & $o_{3}$ & 0.0682 & $2.1149 * *$ \\
$\boldsymbol{l}_{4}$ & 0.0718 & $2.0241^{* *}$ & $j_{4}$ & 0.0157 & 1.4241 & $o_{4}$ & 0.0655 & 1.8011 \\
$\boldsymbol{l}_{5}$ & 0.0415 & $2.3162^{* * *}$ & $j_{5}$ & 0.1026 & $2.2141^{* *}$ & $o_{5}$ & 0.0642 & $2.2301 * * *$ \\
$\theta_{c}$ & -0.1998 & $-3.4257^{* * *}$ & $\theta_{f}$ & -0.1659 & $-2.5492^{* *}$ & $\theta_{N}$ & -0.1802 & $-3.4125^{* * *}$ \\
& & & & & & & \\
$\delta_{c}^{2}$ & 0.0918 & $2.7125^{* * *}$ & $\delta_{f}^{2}$ & 0.1008 & $3.4125^{* *}$ & $\delta_{N}^{2}$ & 0.1642 & $3.7128^{* * *}$ \\
& & & & & & & \\
$\lambda_{c 0}$ & 0.1005 & $3.8125^{* * *}$ & $\lambda_{f 0}$ & 0.1672 & $2.0512^{* *}$ & $\lambda_{N 0}$ & 0.1338 & $2.6059 * * *$ \\
$\lambda_{c 1}$ & 0.8012 & $2.7156^{* * *}$ & $\lambda_{f 1}$ & 0.9015 & $3.0115^{* * *}$ & $\lambda_{N 1}$ & 0.8872 & $3.3315^{* * *}$ \\
$\lambda_{c 2}$ & 0.7062 & $3.3015^{* * *}$ & $\lambda_{f 2}$ & 0.6241 & $3.3142^{* * *}$ & $\lambda_{N 2}$ & 0.4815 & $3.4152^{* * * *}$ \\
\hline & & & & & & \\
\hline
\end{tabular}

Note: $* * * * *$ and $*$ denote the significant at the $1 \%, 5 \%$ and $10 \%$ level, respectively.

futures is larger than that of S\&P500 index cash market, it can be seen that the frequency of jumps during the event is larger in S\&P500 stock index futures and NASDAQ stock index futures market. $\lambda_{0}, \lambda_{1}$ and $\lambda_{2}$ are all in accordance with $\lambda_{0}>0, \lambda_{1} \geq \lambda_{2}$ and $\lambda_{2}>0$, satisfying the sufficient condition hypothesis of positive jump frequency.

In terms of jump size, the mean $(\theta)$ and variance $\left(\delta^{2}\right)$ of the jump sizes of S\&P500 stock index futures and NASDAQ stock index futures are both significant at the significant levels of $1 \%$ and $5 \%$. It means that there is abnormal information in the three rates of return caused by the instantaneous jump behavior. Among them, the mean $(\theta)$ of instantaneous jumps caused by abnormal information ranges from -0.1998 to -0.1659 , indicating the negative impact of jumps caused by abnormal information on returns while the volatility $\left(\delta^{2}\right)$ of the instantaneous jumps caused by abnormal information ranged from 0.0918 to 0.1642 . Moreover, the largest variation was found in the NASDAQ stock index futures market. Implying that abnormal information has caused the greatest volatility in the NASDAQ stock index futures market. Based on the above, the estimation results of the jump size and jump frequency of the return rate of stock index in each market, and the discontinuous jump process is an important factor affecting the return rate that cannot be ignored. 


\section{B. Own-Spillover Effects of Returns in Each Market}

As shown in Table 6, it can be found that the return of S\&P500 index cash is positively affected by the previous one, two and five periods of the cash return itself, and its estimated coefficients $\left(\phi_{1}, \phi_{2}\right.$, $\left.\phi_{5}\right)$ are statistically significant at the $1 \%$ and $5 \%$ levels. The return of S\&P500 stock index futures is positively affected by its previous one, two, four and five periods of the futures return itself, and its estimated coefficients $\left(b_{2}, b_{4}, b_{5}\right)$ are all statistically significant at a level of $5 \%$. The return of NASDAQ stock index futures is positively affected by the previous one and four periods of the futures return itself, and its estimated coefficients $\left(m_{1}, m_{4}\right)$ are significant at the significant levels of $1 \%$ and $5 \%$. All the above results indicate that the return of stock index in the three markets has obvious own-spillover effect, which means that the investing public can adopt positive investment strategy when using historical stock index return to predict future stock index return, which is helpful to increase the possibility of profit.

\section{Cross-Market Spillover Effects of Returns in Each Market}

It can be found in Table 6, the return of the S\&P500 index cash is significantly affected by the previous one and two periods of the return of S\&P500 index futures and the previous two and five periods of the return of NASDAQ index futures. The estimated coefficients $\left(\kappa_{1}, \kappa_{2}\right.$ and $\left.l_{2}, l_{5}\right)$ are statistically significant at the levels of $1 \%$ and $5 \%$. The return of the S\&P500 index futures is significantly affected by the previous two, four and five periods of the return of S\&P500 index cash and the previous two, three and five periods of the return of NASDAQ index futures. The estimated coefficients $\left(\varsigma_{2}, \varsigma_{4}, \varsigma_{5}\right.$ and $j_{2}$, $\left.j_{3}, j_{5}\right)$ are statistically significant at the levels of $1 \%$ and $5 \%$. The return of the NASDAQ index futures is significantly affected by the previous two and four periods of the return of S\&P500 index cash and the previous two, three and five periods of the return of S\&P500 index futures. The estimated coefficients $\left(p_{2}, p_{4}\right.$ and $\left.o_{2}, o_{3}, o_{5}\right)$ are statistically significant at the levels of $1 \%$ and $5 \%$. Based on the above discussions, there are two-way lead and lag relationships among US S\&P500 stock index cash, futures and NASDAQ stock index futures markets (i.e. bidirectional causality) each other, indicating that each index return can play as price discovery function role.

D. Dynamic Adjustment Effects from Short-term Disequilibrium to Long-run Equilibrium

As indicated in Table 6, the corresponding coefficients $\left(\gamma_{1}, \gamma_{2}, \gamma_{3}\right)$ of error correction term $z_{t-1}$ are negative and significant at the $1 \%$ and 5\% significance levels. The market satisfies long-term general equilibrium conditions and possess certain degree of co-integration meaning that due to external impact, S\&P500 stock index cash and futures and NASDAQ stock index futures markets can then restore to long-term equilibrium relationship after dynamic adjustment of error correction term. Representing that rate of return of the three markets has co-movement trend. Change of series for the three different rate of returns is affected by their lagged period respectively. After comparing the size of adjustment coefficients 
$\left(\gamma_{1}=-0.0242, \gamma_{2}=-0.0152\right.$ and $\left.\gamma_{3}=-0.0452\right)$ of the three markets during the estimation period (take the absolute value), we can find that the adjustment coefficient of the return of US S\&P500 index futures is the smallest, representing that when the US S\&P500 stock index cash and futures and NASDAQ stock index futures markets are deviating from long-term equilibrium relationship due to unexpected shock, the US S\&P500 stock index futures market can then adjust to the original long-term equilibrium situation faster in comparison with the US S\&P500 stock index cash and NASDAQ stock index futures markets. This would mean that the US S\&P500 stock index futures market plays a relatively dominant role in affecting the other markets under our model development and estimated period.

\section{(2) Results of Conditional Variance Equations}

This study uses the conditional variance equation in the ARJI VEC GJR-GARCH model to capture the volatility behavior of the S\&P500 stock index cash, futures and NASDAQ stock index futures returns.

\section{A. Own-Market Volatility Effects (GARCH effects)}

According to Table 7, it can be found that the conditional variance of the return of S\&P500 index cash and futures and NASDAQ index futures are positively affected by the conditional variance of the previous period. The estimated coefficients $\left(\alpha_{\epsilon}, \alpha_{f}, \alpha_{N}\right)$ are all significant at the $1 \%$ level, which means that the current conditional variance of the stock index returns of the three markets can be predicted by their own previous conditional variances. There are obvious own-volatility (GARCH) effect. Among them, NASDAQ stock index futures have the most obvious effect of own-volatility, which means that the NASDAQ stock index futures market has the largest risk adjustment.

Table 7: Estimated Results of the Conditional Variance Equations

\begin{tabular}{ccccccccc}
\hline & $h_{c, t}$ & t-value & & $h_{f, t}$ & t-value & & $h_{N, t}$ & t-value \\
\hline$w_{1}$ & 0.0312 & 0.2911 & $w_{2}$ & 0.0168 & 0.5582 & $w_{3}$ & 0.0032 & 0.3462 \\
$\alpha_{c}$ & 0.7721 & $3.7158 * * *$ & $\alpha_{f}$ & 0.8015 & 3.7828 & $\alpha_{N}$ & 0.8506 & $3.9542 * * *$ \\
$f_{c f}$ & 0.0641 & $2.0152 * *$ & $f_{f c}$ & 0.0036 & $2.1145^{* *}$ & $f_{N c}$ & 0.0056 & 0.9153 \\
$g_{c N}$ & 0.0412 & 0.3925 & $g_{f N}$ & 0.0230 & 0.4138 & $g_{N f}$ & 0.0201 & $2.3322^{* * *}$ \\
$\beta_{c}$ & 0.0715 & $2.7252 * * *$ & $\beta_{f}$ & 0.0695 & $2.7038^{* * *}$ & $\beta_{N}$ & 0.0644 & $1.9124 * *$ \\
$\varphi_{1}$ & 0.0765 & $3.7082 * * *$ & $\varphi_{2}$ & 0.1582 & $3.4015 * * *$ & $\varphi_{3}$ & 0.0815 & $3.5520^{* * *}$ \\
\hline
\end{tabular}

Note: $* * *, * *$ and $*$ denote the significant at the $1 \%, 5 \%$ and $10 \%$ level, respectively. 


\section{B. Unexpected Shocks on Volatility (ARCH effects)}

According to Table 7, it can be found that the conditional variance of the returns of S\&P500 index cash and futures and NASDAQ index futures have volatility shock effects, and the estimated coefficients $\left(\beta_{c}, \beta_{f}, \beta_{N}\right)$ are significantly positive at the $1 \%$ and $5 \%$ significance levels. That is to say, there are obvious ARCH effects, showing that the variance of stock index returns is affected by unexpected shocks and produce volatilities. Among them, the S\&P500 index cash market has the most obvious impact of volatility, which means that the new information has the greatest impact on the S\&P500 index cash market. Therefore, the adjustments of S\&P500 index futures and NASDAQ index futures markets when affected by new information are relatively small (or stable). In this way, using these two futures market information as hedging tools is effective in risk management.

\section{Cross-Market Volatility Spillover Effects}

Regarding cross- or inter-market volatility effects, as indicated in Table 7, the volatility of the S\&P500 index cash market is positively affected by the volatility of the S\&P500 index futures. The estimated coefficient is $\left(f_{c f}, 0.0036\right)$ is significant under the $5 \%$ significant level. It is pointed out that the volatility of the S\&P500 index cash market can be predicted by the volatility of S\&P500 stock index futures market. The volatility of the S\&P500 index futures is positively affected by the volatility of the S\&P500 index cash, and its estimated coefficient $\left(f_{f c^{\circ}}, 0.0230\right)$ is significant under the $5 \%$ significant level. It indicates that the volatility of the S\&P500 index futures can be predicted by the volatility of S\&P500 stock index cash market. The volatility of NASDAQ index futures is significantly positively affected by the volatility of S\&P500 index futures. The estimated coefficient $\left(g_{N f}, 0.0201\right)$ is significant under the $1 \%$ significant level. It signifies that the volatility of NASDAQ index futures market can be predicted by the volatility of S\&P500 index futures market. We find two-way volatility spillovers between the stock markets of the S\&P500 index cash and S\&P500 index futures and only one-way volatility spillover from the S\&P500 index futures market to NASDAQ index futures market. International investors need to consider the information from the own-market volatility (risk) but also the volatility spillover (risk) from the other stock markets.

\section{Asymmetric Effects of Own-Market Volatility}

The asymmetric impacts of bad and good news were estimated and also indicated in Table 7. All estimated asymmetric coefficients $\left(\varphi_{1}=0.1916\right.$ for the S\&P500 index cash, $\varphi_{2}=0.2070$ for the S\&P500 index futures and $\varphi_{3}=0.2636$ for the NASDAQ index futures) are positive significantly at $1 \%$ level. Asymmetric effects exist in return volatility for these three stock markets. This means that unexpected negative shocks (bad news) has a greater impact on volatility than unexpected positive shocks (good news). Therefore, when making decisions, investors need consider the impacts of good and bad news on these three market before they can make the best investment strategy. 


\section{(3) Results of Conditional Co-variance Equations}

Table 8 shows the estimated coefficients of the conditional covariation equations for the returns of the S\&P500 index cash, S\&P500 index futures and NASDAQ index futures. As indicated in Table 8, it can be seen that the estimated coefficients $\left(m_{1,2}, m_{2,3}\right)$ of the conditional covariance between the return of S\&P500 index cash and the return of S\&P500 index futures as well as the return of S\&P500 index futures and the return of NASDAQ index futures are affected significantly by their past period of own-conditional covariance at the 5\% significance level. Indicating that the conditional covariance between the return of S\&P500 index cash and the return of S\&P500 index futures as well as the return of S\&P500 index futures and the return of NASDAQ index futures have an own-covariance effect. Changes in the returns of the S\&P500 index cash, S\&P500 index futures and NASDAQ index futures between the each two markets are related and affect each other.

Table 8: Estimated Results of the Conditional Co-variance Equations

\begin{tabular}{lllllllll}
\hline & $h_{c f, t}$ & t-value & & $h_{c N, t}$ & t-value & & $h_{f N, t}$ & t-value \\
\hline$N_{1,2}$ & 0.0426 & 0.5156 & $N_{1,3}$ & 0.0523 & 0.2712 & $N_{2,3}$ & 0.0301 & 1.4563 \\
$m_{1,2}$ & 0.4045 & $2.6896 * * *$ & $m_{1,3}$ & 0.3014 & 1.3245 & $m_{2,3}$ & 0.1978 & $2.2264 * * *$ \\
$v_{1,2}$ & 0.0786 & $2.0988^{* *}$ & $v_{1,3}$ & 0.0812 & $2.0856^{* *}$ & $v_{2,3}$ & 0.0643 & $2.3125^{* * *}$ \\
\hline
\end{tabular}

Note: $* * * * *$ and $*$ denote the significant at the $1 \%, 5 \%$ and $10 \%$ level, respectively.

However, the conditional covariance between the return of S\&P500 index cash and the return of NASDAQ index futures is not affected significantly by their past period of own-conditional covariance. In addition, the conditional covariance between each pair of markets for S\&P500 stock index cash and futures and NASDAQ stock index futures can be positively affected by the their residual cross-terms $\left(\varepsilon_{\varepsilon_{t} t-1} \varepsilon_{f, t-1}, \varepsilon_{\varepsilon_{t} t-1} \varepsilon_{N_{t} t-1}, \varepsilon_{f, t-1} \varepsilon_{N_{a} t-1}\right)$ since the estimated coefficients $\left(v_{1,2}, v_{1,3}, v_{2,3}\right)$ are positive and significant at $1 \%$ or $5 \%$ level. That is, when unexpected shocks or new information is added, the interaction (correlation) between each pair of markets will increase.

\section{(4) Diagnostic Checking for Goodness-of-fit of the Estimated Model}

In order to check the adequacy of the model, in this study we used the Ljung-Box Q test to calculate the standardized residuals and squared residuals and cross-product of standardized residuals. As indicated in Table 9, all results of Ljung-Box $Q$ tests $(\mathrm{Q}(12), \mathrm{Q}(18))$ fail to reject the null hypothesis that the estimated standardized residuals $\left(Z_{c, t}, Z_{f, t}\right.$ and $\left.Z_{N_{i, t}}\right)$, squared standardized residuals $\left(\mathrm{Z}_{c_{0, t},}^{2}, \mathrm{Z}_{f, t}^{2}\right.$ and $\left.\mathrm{Z}_{N_{0}, t}^{2}\right)$ and cross-product of the two standardized residuals $\left(Z_{c_{0, t},} Z_{f_{t}, t}, Z_{c_{c} t} Z_{N_{s} t}\right.$ and $\left.Z_{f, t} Z_{N_{0} t}\right)$ have no autocorrelation and ARCH effects. The tests for the presence of asymmetric behavior of volatility (SBT, NSBT, PSBT and JT) on the estimated standardized residuals, it shows no asymmetric effect of volatility for the estimated model. Therefore, these above tests verify that the ARJI VEC GJR-GARCH model we estimated is an appropriate specification for these three stock markets and the empirical results are also useful and applicable. 
Table 9: Goodness-of-Fit Test and Diagnostic Checking

\begin{tabular}{llll}
\hline & $Z_{c, t}=\hat{\varepsilon}_{c, t} / \sqrt{h_{c, t}}$ & $Z_{\mathrm{f}, t}=\hat{\varepsilon}_{\mathrm{f}, t} / \sqrt{h_{\mathrm{f}, t}}$ & $Z_{\mathrm{N}, t}=\hat{\varepsilon}_{\mathrm{N}, t} / \sqrt{h_{\mathrm{N}, t}}$ \\
\hline$Q(12)$ & 10.3954 & 10.9125 & 7.9696 \\
$Q(18)$ & 19.2185 & 16.4157 & 17.9125 \\
\hline & $Z_{c, t}{ }^{2}$ & $Z_{\mathrm{f}, t}{ }^{2}$ & $Z_{\mathrm{N}, t}{ }^{2}$ \\
\hline$Q(12)$ & 9.9825 & 14.3988 & 15.9254 \\
$Q(18)$ & 12.0078 & 16.9154 & 17.9515 \\
\hline & $Z_{c, t} Z_{\mathrm{f}, t}$ & $Z_{c, t} Z_{\mathrm{N}, t}$ & $Z_{\mathrm{f}, t} Z_{\mathrm{N}, t}$ \\
\hline$Q(12)$ & 12.687 & 12.006 & 11.061 \\
$Q(18)$ & 13.993 & 14.882 & 12.211 \\
\hline & $Z_{c, t}$ & $Z_{\mathrm{f}, t}$ & $Z_{\mathrm{N}, t}$ \\
SBT & 0.9923 & 1.1452 & 0.9425 \\
NSPT & 0.8521 & 0.7272 & 0.5532 \\
PSBT & 0.3049 & 0.2205 & 1.0121 \\
JT & 1.3946 & 1.7238 & 1.9503 \\
\hline
\end{tabular}

Note: $1 . Z_{i, t}=\varepsilon_{i, t} / \sqrt{\operatorname{var}\left(\varepsilon_{i, t}\right)}, Z_{i_{t}}^{2}$ and $Z_{i, t} Z_{j, t}$ represent standardized residuals, squared standardized residuals and cross-product of standardized residuals, respectively.

2. SBT, NSBT, PSBT are tested by t-values, and JT is by F-value.

3. ***, ** and $*$ denote the significant at the $1 \%, 5 \%$ and $10 \%$ level, respectively.

\section{(5) Results and Analysis of Hedging Ratio and Performance}

Johnson (1960), Stein (1961) and Ederington (1979) used Markowitz's (1952) mean-variance method to measure risk by the variance of the investment portfolio. And applied to the hedging of spot positions, the hedging ratio that minimizes the variance can be obtained. Assuming that an investment portfolio contains $C_{s}$ units of spot and $C_{f}$ units of futures, and the prices of spot and futures at time $\mathrm{t}$ are $S_{t}$ and $F_{t}$, respectively, the rate of return of this hedging investment portfolio can be expressed in equation (25):

$$
R_{h}=R_{s}-h R_{f}
$$

If the hedger sells h-unit futures positions to hedge, the equation for the minimum variance of the hedge portfolio is as shown in equation (26):

$$
\min _{h} \operatorname{Var}\left(R_{h}\right)=\operatorname{Var}\left(R_{s}\right)+h^{2} \operatorname{Var}\left(R_{f}\right)-2 h \operatorname{Cov}\left(R_{s}, R_{f}\right)
$$

Take the first-order derivative of the above equation to the hedge ratio $\mathrm{h}$, and making it equal to zero. The optimal hedging ratio that minimizes the variance of the hedging portfolio can be obtained, which is called the minimum variance hedge ratio (MV hedge ratio) as in equation (27): 


$$
h^{M V}=\frac{\operatorname{Cov}\left(R_{s}, R_{f}\right)}{\operatorname{Var}\left(R_{f}\right)}=\frac{\sigma_{s f}}{\sigma_{f}^{2}}=\rho \frac{\sigma_{s}}{\sigma_{f}}
$$

Where $\rho$ and $\sigma_{s f}$ are the correlation coefficient and covariance of $\sigma_{s}$ and $\sigma_{f}$ respectively, and $\sigma_{s}$ and $\sigma_{f}$ are the standard deviations of cash return $R_{s}$ and futures return $R_{f}$, respectively.

This study adopts the ARJI model of Chan and Maheu (2002) and Maheu and McCurdy (2004), sets the rate of return to capture discontinuous jumps, and incorporates the rate of return into the calculation of the hedging ratio, including the jumped hedging ratio in equation (28):

$$
h^{J}=\frac{\operatorname{Cov}\left(R_{s}, R_{f}\right)}{\operatorname{Var}\left(R_{f}\right)}=\rho \frac{\sqrt{\sigma_{s}^{2}+\left(\theta_{s}^{2}+\delta_{s}^{2}\right) \lambda_{s}}}{\sqrt{\sigma_{f}^{2}+\left(\theta_{f}^{2}+\delta_{f}^{2}\right) \lambda_{f}}}
$$

Where $\theta_{s}, \theta_{f}, \delta_{s}^{2}$ and $\delta_{f}^{2}$ are the mean and variance of spot and futures, $\lambda_{s}$ and $\lambda_{f}$ are the jump intensity of spot and futures returns, respectively. In equation (28), if the jump intensity is not taken into consideration, $\lambda_{s}=\lambda_{f}=0$, then the optimal hedge ratio will be simplified to the MV hedge ratio in the above equation (27).

The measure of hedging performance is the degree of reducing the variance of the expected return of unhedged spot positions. The greater the degree of decrease, the better the hedging effect. The hedging index (HE) to measure the performance of hedging is as equation (29):

$$
H E=\frac{\operatorname{Var}\left(R_{s}\right)-\operatorname{Var}\left(R_{h p}\right)}{\operatorname{Var}\left(R_{s}\right)}
$$

Theoretically, the level of hedging performance is determined by the degree of reduction in $\operatorname{Var}\left(R_{h p}\right)$. If the jump intensity is not considered, the degree of reduction of $\operatorname{Var}\left(R_{h p}\right)$ is mainly determined by the hedging ratio and the variance between markets. Because there may be abnormal information in the market, this study expects to capture it through the settings of the ARJI model. Therefore, if investors have a hedging demand, the calculation method of the hedging ratio should adopt the hedging ratio that includes jumps.

According to the model of the jump hedging ratio and hedging performance mentioned in this section, the S\&P500 stock price index futures are used as the direct hedging object, and the NASDAQ stock index futures are further added as the cross hedging object to estimate the hedging performance. The optimal hedging ratio and hedging performance are listed in Table 10. By observing the hedging ratio, it can be found that both direct hedging ratio and cross hedging ratio are less than 1 . That is, there is no need to hedge the spot position $100 \%$, which can save part of the hedging cost of investors. In terms of 
hedging performance, the direct hedging with S\&P500 stock index futures is better than the cross hedging with NASDAQ stock index futures.

Table 10: Optimal Hedging Ratio and Hedging Performance under Dynamic Jump Intensity

\begin{tabular}{lll}
\hline & Direct-Hedging & Cross-Hedging \\
\hline Hedging Ratio & 0.9269 & 0.7469 \\
Hedging Performance & 0.9417 & 0.6735 \\
\hline
\end{tabular}

\section{Concluding Remarks}

This study develops an ARJI VEC GJR-GARCH model to simultaneously investigate the dynamic process of the co-integration, volatility spillover, jump behavior and hedge performance of the US S\&P500 stock index cash and futures and NASDAQ stock index futures markets. The main findings and conclusions are summarized as follows:

The co-integration relationship between S\&P500 spot and futures and NASDAQ stock index futures has been tested and found that there is indeed a long-term equilibrium co-integration relationship among the three markets and there is obviously a set of co-integration vectors. This co-integration relationship means that individual markets may have their own different fluctuations in a short period, but the long-term stock price trend shows a co-movement trend with each market driving other markets under mutual influence. Therefore, error correction term should be incorporated into the model so that the short-term dynamic will not deviate too much from the long-term equilibrium. The long-term equilibrium relationship ensures the existence of a causal relationship between futures and spot prices within these three markets.

Regarding cross- or inter-market volatility spillover effects, we find a two-way volatility spillovers between the stock markets of the S\&P500 index cash and S\&P500 index futures and only one-way volatility spillover from the S\&P500 index futures market to NASDAQ index futures market. Domestic or international investors need to consider the information from the own-market volatility (risk) but also the volatility spillover (risk) from the other stock markets.

Basically, there is indeed a discontinuous jump phenomenon and behavior among the three markets. The jump frequency (jump intensity) is not a fixed constant during the estimation, that is, the jump frequency (jump intensity) generated by the abnormal information changes with time. As for the size of jumps, the mean and variance of the returns of US S\&P500 stock index cash and futures and NASDAQ stock index futures markets are all significant, which means that there is an instantaneous jump behavior caused by abnormal information in return of these three markets. The empirical results show that the 
discontinuous jump process is an important factor affecting the rate of return of these three markets. Therefore, in order to achieve the best hedging performance, investors should also consider the impact of abnormal information on the market when making investment, arbitrage and hedging portfolios

Finally, based on the results estimated by the ARJI VEC GJR-GARCH model, it also points out that the performance of direct hedging is better than the performance of cross hedging. It is because after adding the jumping factor, the model can better capture the jump diffusion or discontinuity of index returns, and the description or prediction of the return volatility of assets is more accurate, so the hedging performance is better. Therefore, when making investment, arbitrage and hedging portfolios, investors must consider the jumping factors or the time-varying variance of return caused by the jump in the market, that is, the impact of abnormal information on the market in order to achieve the best hedging performance. Furthermore, according to the model of the jump hedging ratio and hedging performance mentioned in this study, the S\&P500 stock price index futures are used as the direct hedging object, and the NASDAQ stock index futures are further added as the cross hedging object to estimate the hedging performance. In terms of hedging performance, when making investment, arbitrage and hedging portfolios, investors need consider the direct hedging with S\&P500 stock index futures is better than the cross hedging with NASDAQ stock index futures

\section{References}

Andersen, T. G., Benzoni, L. and Lund, J. (2002). An empirical investigation of continuous-time equity return models. The Journal of Finance, 57(3), 1239-1284.

Bates, D. S. (1991). The crash of '87: was it expected? The evidence from options markets. The Journal of Finance, 46(3), 1009-1044.

Berndt, E. R., Hall, B. H., Hall, R. E. and Hausman, J. A. (1974). Estimation and inference in nonlinear structural models. Annals of Economic and Social Measurement, 3, 653-665

Bertus, M., Godbey, J. and Hilliard, J. E. (2009). Minimum variance cross hedging under mean-reverting spreads, stochastic convenience yields, and jumps: Application to the airline industry. Journal of Futures Markets, 29(8), 736-756.

Bollerslev, T. (1986). Generalized autoregressive conditional heteroskedasticity. Journal of Econometrics, 31(3), 307-327.

Chan, W. H. and Maheu, J. M. (2002). Conditional jump dynamics in stock market returns. Journal of Business and Economic Statistics, 20(3), 377-389.

Chan, W. H. and Young, D. (2006). Jumping hedges: An examination of movements in copper spot and futures markets. Journal of Futures Market, 26(2), 169-188.

Cheang, G. H., Chiarella, C. and Ziogas, A. (2013). The representation of American options prices under stochastic volatility and jump-diffusion dynamics. Quantitative Finance, 13(2), 241-253.

Craine, R., Lochstoer, L. A. and Syrtveit, K. (2000). Estimation of a stochastic-volatility jump-diffusion model. Revista de Analisis Economico, 15(1), 61-87.

Creel, M. and Kristensen, D. (2015). ABC of SV: Limited information likelihood inference in stochastic volatility jump-diffusion models. Journal of Empirical Finance, 31, 85-108. 
Das, S. R. (2002). The surprise element: jumps in interest rates. Journal of Econometrics, 106(1), 27-65.

Ederington, L. H. (1979). The hedging performance of the new futures markets. The Journal of Finance, 34(1), 157-170.

Engle, R. F. (1982). Autoregressive conditional heteroscedasticity with estimates of the variance of United Kingdom inflation. Econometrica, 50, 987-1007.

Engle, R. F. and Ng, V. K. (1993). Measuring and testing the impact of news on volatility. The Journal of Finance, 48(5), 1749-1778.

Eraker, B. (2004). Do stock prices and volatility jump? Reconciling evidence from spot and option prices. The Journal of Finance, 59(3), 1367-1403.

Fama, E. F. (1965). The behavior of stock-market prices. The Journal of Business, 38(1), 34-105.

Fan, C., Luo, X. and Wu, Q. (2017). Stochastic volatility vs. jump diffusions: Evidence from the Chinese convertible bond market. International Review of Economics and Finance, 49, 1-16.

Fortune, P. (1999). Are stock returns different over weekends? A jump diffusion analysis of the weekend effect. New England Economic Review, 10, 3-19.

Glosten, L. R., Jagannathan, R. and Runkle, D. E. (1993). On the relation between the expected value and the volatility of the nominal excess return on stocks. The Journal of Finance, 48(5), 1779-1801.

Johnson, L. L. (1960). The theory of hedging and speculation in commodity futures. Review of Economic Studies, 27: 139-151.

Kaeck, A. and Alexander, C. (2012). Volatility dynamics for the S\&P 500: Further evidence from non-affine, multi-factor jump diffusions. Journal of Banking and Finance, 36(11), 3110-3121.

Koulis, A., Kaimakamis, G. and Beneki, C. (2018). Hedging effectiveness for international index futures markets. Economics and Business, 32(1), 149-159.

Lai, Y. S. (2019). Evaluating the hedging performance of multivariate GARCH models. Asia Pacific Management Review, 24(1), 86-95.

Liu, Q., Chng, M. T. and Xu, D. (2014). Hedging industrial metals with stochastic volatility models. Journal of Futures Markets, 34(8), 704-730.

Maheu, J. M. and McCurdy, T. H. (2004). News arrival, jump dynamics, and volatility components for individual stock returns. The Journal of Finance, 59(2), 755-793.

Markowitz, H. (1952). Portfolio selection. The Journal of Finance, 7: 77-91.

Press, S. J. (1967). A compound events model for security prices. Journal of business, 317-335.

Stein, J. L. (1961). The Simultaneous determination of spot and futures prices. The American Economic Review, 51(5), 1012-1025.

Todorov, V. (2009). Estimation of continuous-time stochastic volatility models with jumps using high-frequency data. Journal of Econometrics, 148(2), 131-148.

Ulyah, S. M., Lin, X. C. S. and Miao, D. W. C. (2018). Pricing short-dated foreign equity options with a bivariate jump-diffusion model with correlated fat-tailed jumps. Finance Research Letters, 24, 113-128.

Zhou, C., Wu, C. and Wang, Y. (2019). Dynamic portfolio allocation with time-varying jump risk. Journal of Empirical Finance, 50, 113-124. 